\title{
Review Article \\ Reduction of Oxygen Impurity in Multicrystalline Silicon Production
}

\author{
Bing Gao, Satoshi Nakano, and Koichi Kakimoto \\ Research Institute for Applied Mechanics, Kyushu University, Kasuga, Fukuoka 816-8580, Japan \\ Correspondence should be addressed to Bing Gao; gaobing@riam.kyushu-u.ac.jp
}

Received 7 December 2012; Accepted 17 January 2013

Academic Editor: Bhushan Sopori

Copyright ( 2013 Bing Gao et al. This is an open access article distributed under the Creative Commons Attribution License, which permits unrestricted use, distribution, and reproduction in any medium, provided the original work is properly cited.

\begin{abstract}
Effective control of oxygen impurity in multicrystalline silicon is required for the production of a high-quality crystal. The basic principle and some techniques for reducing oxygen impurity in multicrystalline silicon during the unidirectional solidification process are described in this paper. The oxygen impurity in multicrystalline silicon mainly originates from the silica crucible. To effectively reduce the oxygen impurity, it is essential to reduce the oxygen generation and enhance oxygen evaporation. For reduction of oxygen generation, it is necessary to prevent or weaken any chemical reaction with the crucible, and for the enhancement of oxygen evaporation, it is necessary to control convection direction of the melt and strengthen gas flow above the melt. Global numerical simulation, which includes heat transfer in global furnace, argon gas convection inside furnace, and impurity transport in both melt and gas regions, has been implemented to validate the above methods.
\end{abstract}

\section{Introduction}

Multicrystalline silicon has now become the main material in the photovoltaic market because of its low production cost and because of the high conversion efficiency of solar cells made from this material. The unidirectional solidification method is a cost-effective technique for large-scale production of multicrystalline silicon material. Similar to the Czochralski method for crystal growth, the unidirectional solidification method is also related to transport of impurities [1]. Oxygen impurity is one of the main impurities in the crystal. The oxygen impurity can cause $\mathrm{SiO}_{2}$ precipitation [2], dislocation [3], and stacking faults [4] and can cause significant deterioration of the conversion efficiency of solar cells. The degradation of the solar cell performance caused by oxygen has been reported in papers [5-8]. Oxygen precipitation is known to act as intrinsic gettering sites for impurities and to affect mechanical strength of the wafer $[9,10]$. Oxygen can form a variety of inhomogeneous defects: such as thermal donors [11, 12] due to clusters of a few oxygen atoms [13], and some other donors due to $\mathrm{SiO}_{2}$ precipitates [11, 12]. Except for those inhomogeneous defects, there is another kind of uniform distributed defect: boron-oxygen complexes, which is responsible for an asymptotic degradation of solar cell performance by up to $10 \%$ relative when the time scale of illumination is close to hours [14, 15].

Effective control of oxygen concentrations in a crystal is required for the production of a high-quality crystal. Some papers about carbon and oxygen impurities $[1,16-$ 24] have been written by authors; however, until now, there is no review paper to systematically introduce the basic methods to reduce oxygen impurity during multicrystalline silicon production. Therefore, this paper provides a basic framework for oxygen reduction in multicrystalline silicon during the unidirectional solidification process from the view of control of chemical reaction, melt convection, and gas flow. Furthermore, the control of melt convection for oxygen reduction is first reported by the present paper.

\section{Mechanism of Oxygen Incorporation}

Incorporation of oxygen impurity into multicrystalline silicon occurs during the global unidirectional solidification process. To effectively illuminate the mechanism of oxygen incorporation, the global solidification process is divided into several substeps: melting process, solidification process, 
and cooling process. During these processes, there are some differences in the main mechanism of oxygen incorporation into silicon.

2.1. Melting Process. During the melting process, there are two reactions occurring. The first is rapid reaction of the melt silicon with the silica crucible:

$$
\mathrm{Si}(\mathrm{l})+\mathrm{SiO}_{2}(\mathrm{~s})=2 \mathrm{SiO}(\mathrm{g}),
$$

where the symbols (l), (s), and (g) denote liquid phase, solid phase, and gas phase, respectively. The second is decomposition of the silica crucible at a high temperature:

$$
\mathrm{SiO}_{2}(\mathrm{~s})=\mathrm{Si}(\mathrm{l})+2 \mathrm{O}(\mathrm{m}),
$$

where the symbol $(\mathrm{m})$ means the concentration inside the melt.

The silicon and oxygen atoms are transported onto the melt surface and react with each other to produce $\mathrm{SiO}$ gas:

$$
\mathrm{Si}(\mathrm{l})+\mathrm{O}(\mathrm{m})=\mathrm{SiO}(\mathrm{g}) \text {. }
$$

The resultant $\mathrm{SiO}$ gas evaporates from the melt surface. Reaction (2) is usually treated as a main source of oxygen impurity during the global solidification process and reaction (3) is treated as a main mechanism for oxygen reduction.

During the melting process, there is another chemical reaction that can contribute to oxygen incorporation. The graphite susceptor of the crucible can react with the crucible [16]:

$$
\mathrm{C}(\mathrm{s})+\mathrm{SiO}_{2}(\mathrm{~s})=\mathrm{SiO}(\mathrm{g})+\mathrm{CO}(\mathrm{g}) \text {. }
$$

Experimental results [25] have shown that $\mathrm{SiO}$ gas is most likely to be rapidly formed when carbon and silica particles are in contact, and reaction (4) is favorable over the entire temperature range from 1500 to $2500 \mathrm{~K}$. The resultant $\mathrm{SiO}$ gas can diffuse back into melt from the carried gas.

2.2. Solidification Process. During the solidification process, besides reactions (1)-(4), there is another segregation reaction, that is, segregation of oxygen atoms into the crystal:

$$
k_{\text {seg }}{ }^{*} \mathrm{O}(\mathrm{m})=\mathrm{O}(\mathrm{c}),
$$

where the symbol (c) means the concentration in the crystal and $k_{\text {seg }}$ is the segregation coefficient of oxygen, which is taken to be 0.85 [26].

2.3. Cooling Process. During the cooling process, the increase of oxygen impurity in solid phase is mainly due to diffusion from the crucible wall into the crystal. This contribution is very small due to small diffusion coefficient of oxygen in crystal, which is close to $10^{-8} \mathrm{~m}^{2} / \mathrm{s}$ [27]. The diffusion depth of oxygen from the crucible wall is small and can be negligible.

\section{Techniques for Oxygen Reduction and Numerical Models}

The above analysis of oxygen incorporation indicates that oxygen impurity in multicrystalline silicon mainly originates from the silica crucible. To effectively reduce oxygen impurity, it is essential to prevent or reduce any reaction with the crucible, such as reaction between the crucible and silicon and reaction between the crucible and its graphite susceptor. Meanwhile, it is also important to enhance the evaporation of $\mathrm{SiO}$ gas by controlling the melt and gas convection. Therefore, the basic principle for oxygen reduction is to reduce oxygen generation and to increase oxygen evaporation.

Global numerical modeling, which includes heat transfer in global furnace, argon gas convection inside furnace, and impurity transport in both melt and gas regions, has been implemented to validate the above methods.

3.1. Numerical Methodology. Our simulation implementation involves three steps: first, the temperature distribution of furnace components, due to heat transfer and heat radiation, is computed without gas flow; second, the flow field and temperature field of the cooling argon gas are computed using the temperature boundary conditions from the first step; and third, carbon and oxygen impurities in the gas and melt are computed using the flow field and temperature field from the second step.

The modeling of heat transfer in the furnace involves convective heat transfer of the melt in the crucible, conductive heat transfer in all solid components, and radiation heat transfer in all enclosures of the furnace. The melt flow in the crucible is assumed to be an incompressible laminar flow. The radiative heat exchange in all radiative enclosures is modeled on the basis of the assumption of diffuse-gray surface radiation.

The flow of argon gas through the furnace is considered to be a compressible and axisymmetric flow. The compressible flow solver can accurately simulate the buoyancy-driven flow due to the large density variation in the furnace. Although the flow velocity in this furnace is low, yet the density variation is significant for this buoyancy-driven flow, which is similar to the combustion problem.

The concentration of oxygen impurity is calculated by coupling the calculation of carbon impurity inside the global furnace. The $\mathrm{SiO}$ and $\mathrm{CO}$ concentrations inside gas and the $\mathrm{C}$ and $\mathrm{O}$ atom concentrations inside melt are calculated by a set of fully coupled program [1]. The boundary condition of $\mathrm{SiO}$ concentration at the melt surface is obtained from a dynamic update of $\mathrm{SiO}$ concentration [1]. The carbon flux from the gas into the melt is obtained from a local nonequilibrium consideration [1]. The carbon flux at the gas/melt interface is calculated locally and thus carbon accumulation in the melt is included. For details, refer to the paper [1].

\subsection{Techniques for Oxygen Reduction}

3.2.1. Reduction of Oxygen Generation. Since an important source of oxygen impurity in the crystal is the reaction between the crucible and silicon, an effective method to weaken that reaction is to use $\mathrm{Si}_{3} \mathrm{~N}_{4}$ liner along the inner wall of the crucible. This liner can prevent direct contact between the crucible and silicon and thus reduce the intensity of chemical reaction between them. One simulation has been implemented to test the effect of the liner on oxygen impurity 


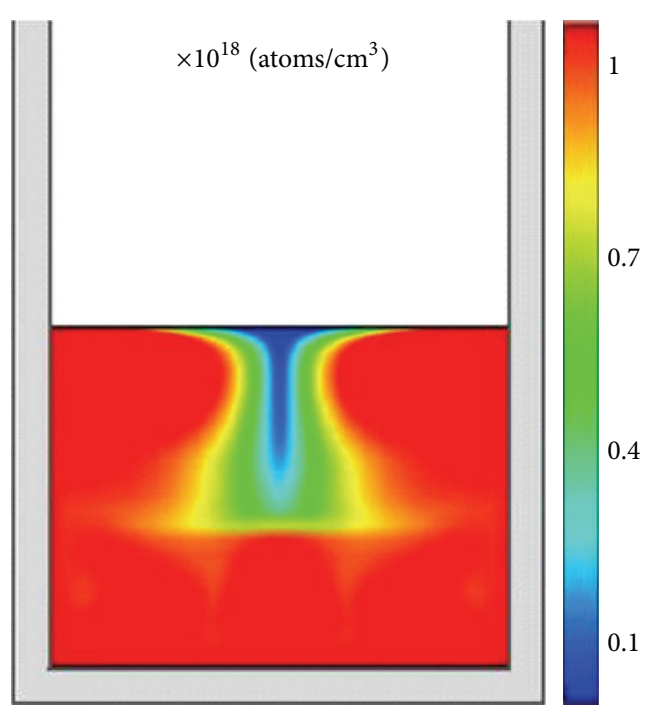

(a)

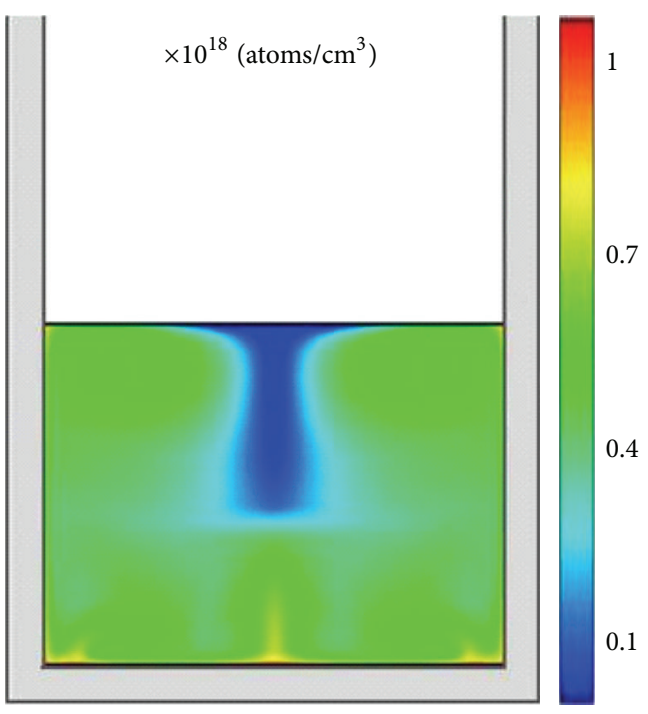

(b)

FIgURE 1: Oxygen concentration distributions inside a silicon crystal for different crucible conditions: (a) without $\mathrm{Si}_{3} \mathrm{~N}_{4}$ liner, (b) with $\mathrm{Si}_{3} \mathrm{~N}_{4}$ liner.

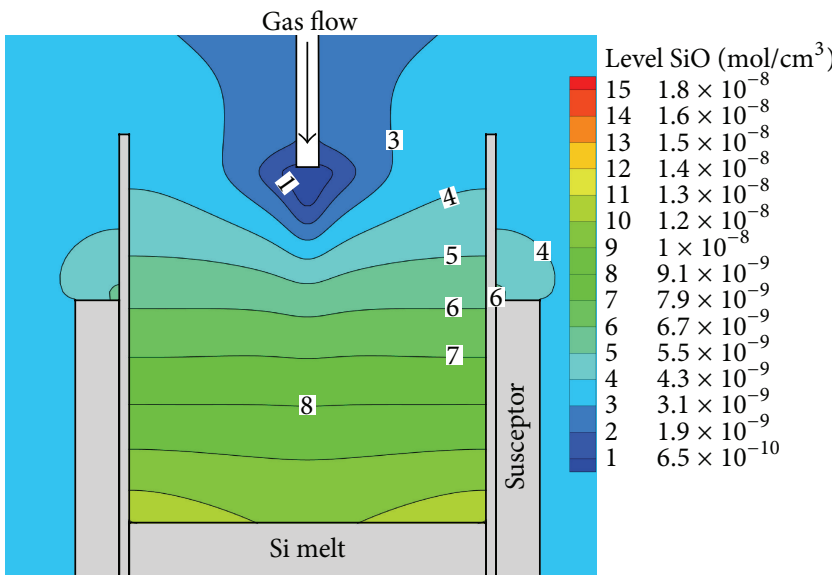

FIGURE 2: SiO gas distribution inside the gas space after considering the reaction between the silica crucible and the susceptor.

in a crystal [28]. The calculated oxygen concentrations in crystal without $\mathrm{Si}_{3} \mathrm{~N}_{4}$ liner (Figure 1(a)) and with $\mathrm{Si}_{3} \mathrm{~N}_{4}$ (Figure 1(b)) liner are shown in Figure 1. It can be seen that the oxygen concentration with $\mathrm{Si}_{3} \mathrm{~N}_{4}$ liner is obviously reduced. The paper [28] has pointed out the possible mechanism of oxygen reduction due to the $\mathrm{Si}_{3} \mathrm{~N}_{4}$ liner. Between the liner and the crucible, one chemical reaction occurs:

$$
\mathrm{Si}_{3} \mathrm{~N}_{4}(\mathrm{~s})+3 \mathrm{SiO}_{2}(\mathrm{~s})=6 \mathrm{SiO}(\mathrm{g})+2 \mathrm{~N}_{2}(\mathrm{~s}) \text {. }
$$

Between the liner and silicon melt, another reaction occurs:

$$
\mathrm{SiO}(\mathrm{g})=\mathrm{Si}(\mathrm{l})+\mathrm{O}(\mathrm{m}) \text {. }
$$

The equilibrium oxygen concentration given from the reactions (6) and (7) at interfaces is about half of that in the case of reaction between a quartz crucible and silicon melt. The equilibrium precondition of the reaction (7) is that the $\mathrm{SiO}$ gas can quickly pass through the $\mathrm{Si}_{3} \mathrm{~N}_{4}$ liner. We can derive that the thickness of $\mathrm{Si}_{3} \mathrm{~N}_{4}$ liner has a direction effect on oxygen reduction, since thicker liner can effectively impede the $\mathrm{SiO}$ gas passing through the liner. Therefore, from the view of point of oxygen reduction, it is more preferable to use thick $\mathrm{Si}_{3} \mathrm{~N}_{4}$ liner.

Oxygen impurity measures at different solidified fraction with $\mathrm{Si}_{3} \mathrm{~N}_{4}$ liner have been implemented in our group [28]. The comparison between the measured data and simulated data shows good agreement under $\mathrm{Si}_{3} \mathrm{~N}_{4}$ liner [28].

Another important source of oxygen impurity is the reaction between the crucible and its graphite susceptor. Numerical simulations have been implemented to test the effect of that reaction on oxygen impurity [16]. The chemical reaction is only considered at triple-phase points, that is, the crossing point among the crucible, susceptor, and gas space. The $\mathrm{SiO}$ distribution inside the gas space is shown in Figure 2. It can be seen that there is a large $\mathrm{SiO}$ concentration at the crossing point, which is $6.7 \times 10^{-9} \mathrm{~mol} / \mathrm{cm}^{3}$. The large concentration can cause $\mathrm{SiO}$ gas to diffuse back into the silicon melt from that triple-phase point and thus cause large oxygen impurity in the melt.

Figure 3 shows the variation of oxygen concentration in the melt with variation of carbon activity at the $\mathrm{SiO}_{2}$ surface [16]. When the carbon activity increases, oxygen impurity in the melt rapidly increases.

The increase of oxygen impurity in melt is due to the rapid generation of $\mathrm{SiO}$ and $\mathrm{CO}$ in gas phase: $\mathrm{C}(\mathrm{s})+\mathrm{SiO}_{2}(\mathrm{~s})=$ $\mathrm{SiO}(\mathrm{g})+\mathrm{CO}(\mathrm{g})$. The resultant $\mathrm{SiO}$ and $\mathrm{CO}$ gases can diffuse back into the melt from the carried gas. Therefore, when carbon activity increases, more $\mathrm{SiO}$ and $\mathrm{CO}$ gases result in and diffuse into melt.

Therefore, an effective method for reducing oxygen impurities in the crystal is to prevent reaction between the silica 


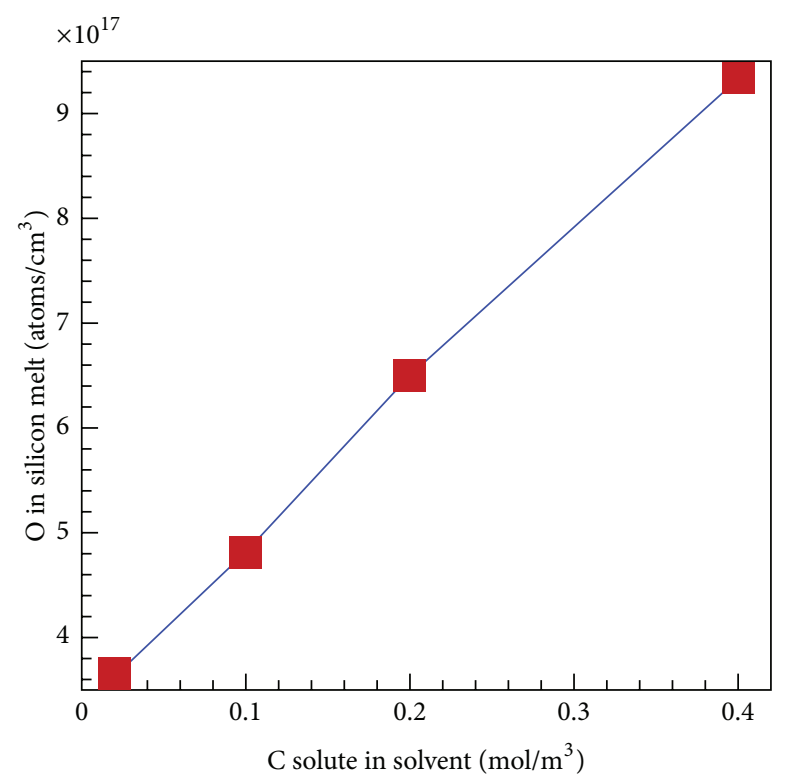

FIgURE 3: Oxygen concentrations in silicon melt with different carbon activities at the $\mathrm{SiO}_{2}$ surface.

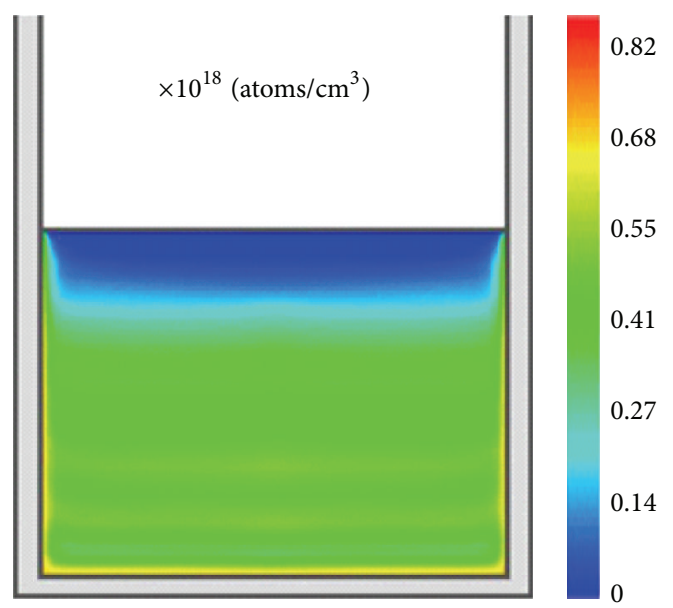

(a)

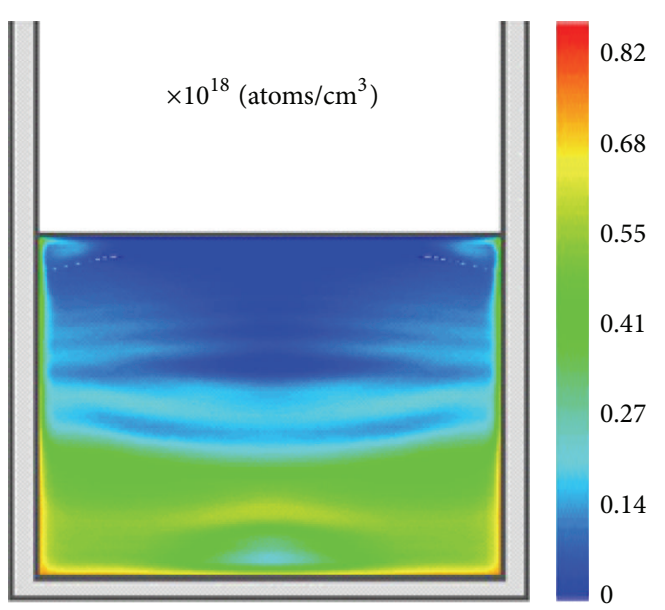

(b)

FIGURE 4: Oxygen concentration distributions inside silicon melt for different convection directions: (a) first from the crucible wall to the bottom and then to the surface, (b) first from the crucible wall to the surface and then to the bottom.

crucible and the graphite susceptor by setting a free space between them or by depositing a layer of $\mathrm{SiC}$ film on the surface of the susceptor.

3.2.2. Enhancement of Oxygen Evaporation. Since reaction (3) is a main source for oxygen evaporation, an effective method for oxygen reduction is to promote evaporation reaction (3). The evaporation speed is determined by the oxygen flux inside the melt and inside the gas. Therefore, it is essential to increase flux in both sides for effective reduction of oxygen impurity.

Inside the melt, the oxygen concentration at the melt surface is always minimal due to evaporation. Thus, the flux along the surface is determined by the concentration just beneath the surface, denoted by $C_{m}$. If $C_{m}$ is large, oxygen flux is definitely large. Therefore, it is essential to increase $C_{m}$ as much as possible to enhance oxygen flux toward the surface. Figure 4 shows oxygen concentration in the melt with different convection patterns. In Figure 4(a), the melt flows first from the crucible wall to the bottom and then to the surface, and in Figure 4(b), the melt flows first from the crucible wall to the surface and then to the bottom. It can be seen that when the melt directly flows from the crucible wall to the surface, the oxygen concentration inside the global melt is obviously small. The main reason is that $C_{m}$ near the surface is larger when the melt directly carries the oxygen 


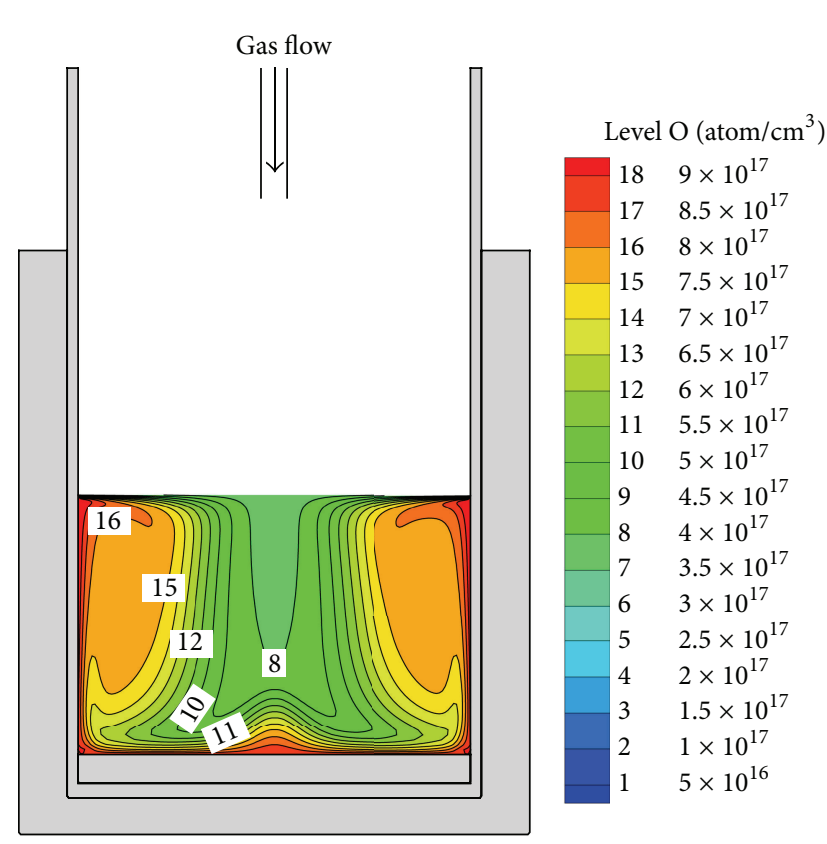

(a)

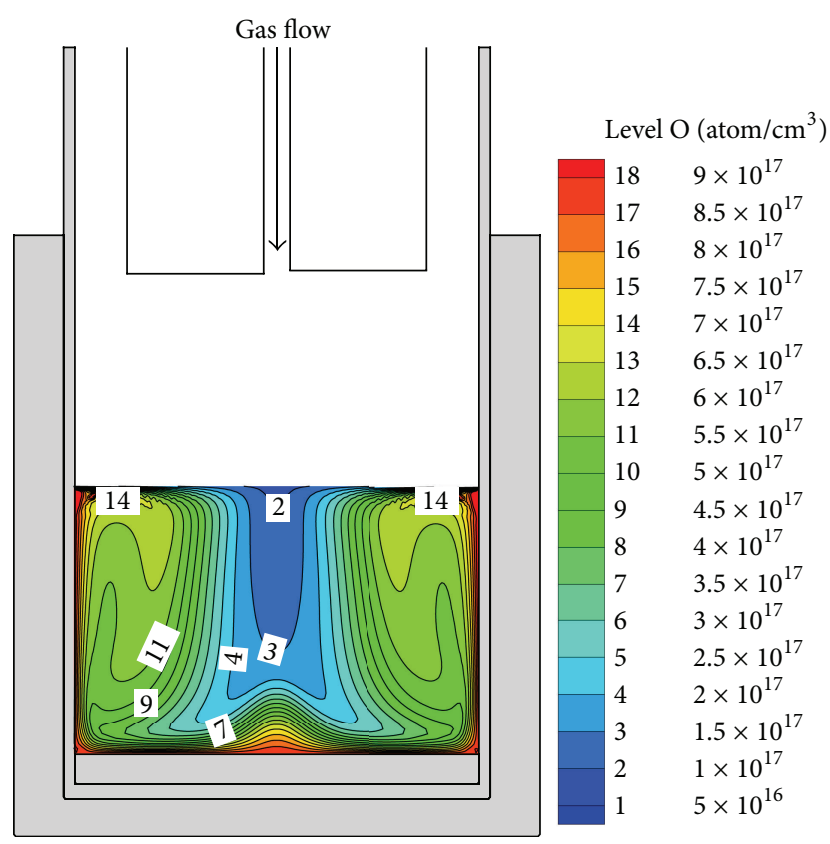

(b)

FIGURE 5: Oxygen concentration distributions inside silicon melt: (a) without a crucible cover, (b) with a crucible cover.

from the crucible wall to the surface. Therefore, the oxygen impurity can be effectively reduced by controlling the flow pattern of the melt.

Inside the gas space, the oxygen concentration at the gas/melt interface is always maximal. Thus, the oxygen flux along the interface is determined by the concentration just above the interface, denoted by $C_{g}$. If $C_{g}$ is small, the flux is definitely large. Therefore, it is essential to reduce that value as much as possible to enhance the evaporation flux. Two numerical simulations have been done with a fixed flow rate of argon gas and temperature boundary conditions. The shape of the gas tube has some difference for the two cases. Figure 5 shows a comparison of oxygen distributions inside the melt without a cover (Figure 5(a)) and with a cover (Figure 5(b)) [18]. It can bee seen that the oxygen concentration is obviously small with a cover. The main reason is that the cover strengthens the flow above the melt, which reduces $C_{g}$ above the interface and causes a large $\mathrm{SiO}$ flux out from the surface. Therefore, the oxygen impurity can be effectively reduced by strengthening the gas flow above the melt.

To indicate the validation of our calculation, some measurements and numerical simulations have been done for the effect of strengthening the gas flow on impurities [1]. The comparison between numerical and experimental results showed good agreement for impurities if the gas flow is strengthened by increasing the gas flow rate [1].

\section{Conclusions}

The oxygen impurity inside multicrystalline silicon mainly originates from the silica crucible. To effectively reduce the oxygen impurity, it is essential to reduce the oxygen generation and enhance oxygen evaporation. For the reduction of oxygen generation, it is necessary to weaken the chemical reaction between the crucible and silicon by using a layer of $\mathrm{Si}_{3} \mathrm{~N}_{4}$ liner and to prevent the reaction between the crucible and the graphite susceptor by setting a free space between them or by depositing a layer of $\mathrm{SiC}$ film on the surface of the susceptor. For the enhancement of oxygen evaporation, it is necessary to increase the oxygen concentration value beneath the melt surface as much as possible by adjusting the convection direction and to reduce the oxygen concentration just above the melt-gas interface as much as possible by strengthening gas flow. The feasibility of the above methods has been validated by the global numerical simulation.

\section{Acknowledgments}

This work was partly supported by the New Energy and Industrial Technology Development Organization (NEDO) under the Ministry of Economy, Trade and Industry (METI).

\section{References}

[1] B. Gao, S. Nakano, and K. Kakimoto, "Global simulation of coupled carbon and oxygen transport in a unidirectional solidification furnace for solar cells," Journal of the Electrochemical Society, vol. 157, no. 2, pp. H153-H159, 2010.

[2] H. J. Möller, L. Long, M. Werner, and D. Yang, "Oxygen and carbon precipitation in multicrystalline solar silicon," Physica Status Solidi, vol. 171, no. 1, pp. 175-189, 1999.

[3] H. J. Möller, C. Funke, A. Lawerenz, S. Riedel, and M. Werner, "Oxygen and lattice distortions in multicrystalline silicon," Solar Energy Materials and Solar Cells, vol. 72, no. 1-4, pp. 403416, 2002.

[4] V. V. Bolotov, M. D. Efremov, I. Babanskaya, and K. Schmalz, "Raman study of mechanical stresses in processes of oxygen 
precipitation in silicon," Materials Science and Engineering B, vol. 21, no. 1, pp. 49-54, 1993.

[5] D. Yang, L. Li, X. Ma, R. Fan, D. Que, and H. J. Moeller, "Oxygen-related centers in multicrystalline silicon," Solar Energy Materials and Solar Cells, vol. 62, no. 1-2, pp. 37-42, 2000.

[6] S. Martinuzzi and I. Perichaud, "Influence of oxygen on external phosphorus gettering in disordered silicon wafers," Materials Science Forum, vol. 143, pp. 1629-1634, 1994.

[7] K. Tempelhoff, F. Speigelberg, R. Gleichmann, and D. Wruck, "Precipitation of oxygen in dislocation-free silicon," Physica Status Solidi A, vol. 56, no. 1, pp. 213-223, 1979.

[8] K. Nauka, H. C. Gatos, and J. Lagowski, "Oxygen-induced recombination centers in as-grown Czochralski silicon crystals," Applied Physics Letters, vol. 43, no. 3, pp. 241-243, 1983.

[9] D. E. Bornside, R. A. Brown, T. Fujiwara, H. Fujiwara, and T. Kubo, "Effects of gas-phase convection on carbon contamination of Czochralski-grown silicon," Journal of the Electrochemical Society, vol. 142, no. 8, pp. 2790-2804, 1995.

[10] U. Gösele and T. Y. Tan, "Oxygen diffusion and thermal donor formation in silicon," Applied Physics A, vol. 28, no. 2, pp. 79-92, 1982.

[11] W. Bergholz, "Chapter 12 grown-in and process-induced defects," Semiconductors and Semimetals, vol. 42, no. C, pp. 513$575,1994$.

[12] A. Borghesi, B. Pivac, A. Sassella, and A. Stella, "Oxygen precipitation in silicon," Journal of Applied Physics, vol. 77, no. 9, pp. 4169-4244, 1995.

[13] J. Michel and L. C. Kimerling, "Electrical properties of oxygen in silicon," Semiconductors and Semimetals, vol. 42, no. C, pp. 251-287, 1994.

[14] J. Schmidt, "Light-induced degradation in crystalline silicon solar cells," Solid State Phenomena, vol. 95, pp. 187-196, 2004.

[15] J. Schmidt and K. Bothe, "Structure and transformation of the metastable boron- and oxygen-related defect center in crystalline silicon," Physical Review B, vol. 69, no. 2, Article ID 024107, pp. 241071-241078, 2004.

[16] B. Gao, S. Nakano, and K. Kakimoto, "Influence of reaction between silica crucible and graphite susceptor on impurities of multicrystalline silicon in a unidirectional solidification furnace," Journal of Crystal Growth, vol. 314, no. 1, pp. 239-245, 2011.

[17] B. Gao, S. Nakano, and K. Kakimoto, "Effect of crucible cover material on impurities of multicrystalline silicon in a unidirectional solidification furnace," Journal of Crystal Growth, vol. 318, no. 1, pp. 255-258, 2011.

[18] B. Gao, X. J. Chen, S. Nakano, and K. Kakimoto, "Crystal growth of high-purity multicrystalline silicon using a unidirectional solidification furnace for solar cells," Journal of Crystal Growth, vol. 312, no. 9, pp. 1572-1576, 2010.

[19] B. Gao and K. Kakimoto, "Global simulation of coupled carbon and oxygen transport in a Czochralski furnace for silicon crystal growth," Journal of Crystal Growth, vol. 312, no. 20, pp. 29722976, 2010.

[20] Y. Y. Teng, J. C. Chen, C. W. Lu, and C. Y. Chen, "Numerical investigation of oxygen impurity distribution during multicrystalline silicon crystal growth using a gas flow guidance device," Journal of Crystal Growth, vol. 360, no. 1, pp. 12-17, 2012.

[21] A. D. Smirnov and V. V. Kalaev, "Development of oxygen transport model in Czochralski growth of silicon crystals," Journal of Crystal Growth, vol. 310, no. 12, pp. 2970-2976, 2008.

[22] C. Reimann, M. Trempa, T. Jung, J. Friedrich, and G. Müller, "Modeling of incorporation of O, N, C and formation of related precipitates during directional solidification of silicon under consideration of variable processing parameters," Journal of Crystal Growth, vol. 312, no. 7, pp. 878-885, 2010.

[23] T. Carlberg, T. B. King, and A. F. Witt, "Dynamic oxygen equilibrium in silicon melts during crystal growth by the czochralski technique," Journal of the Electrochemical Society, vol. 129, no. 1, pp. 189-193, 1982.

[24] D. E. Bornside, R. A. Brown, T. Fujiwara, H. Fujiwara, and T. Kubo, "Effects of gas-phase convection on carbon contamination of Czochralski-grown silicon," Journal of the Electrochemical Society, vol. 142, no. 8, pp. 2790-2804, 1995.

[25] A. W. Weimer, K. J. Nilsen, G. A. Cochran, and R. P. Roach, "Kinetics of carbothermal reduction synthesis of beta silicon carbide," AIChE Journal, vol. 39, no. 3, pp. 493-503, 1993.

[26] K. Hoshikawa and X. Huang, "Oxygen transportation during Czochralski silicon crystal growth," Materials Science and Engineering $B$, vol. 72, pp. 73-79, 2000.

[27] S. Hisamatsu, H. Matsuo, S. Nakano, and K. Kakimoto, "Numerical analysis of the formation of $\mathrm{Si}_{3} \mathrm{~N}_{4}$ and $\mathrm{Si}_{2} \mathrm{~N}_{2} \mathrm{O}$ during a directional solidification process in multicrystalline silicon for solar cells," Journal of Crystal Growth, vol. 311, no. 9, pp. 26152620, 2009.

[28] H. Matsuo, R. B. Ganesh, S. Nakano et al., "Thermodynamical analysis of oxygen incorporation from a quartz crucible during solidification of multicrystalline silicon for solar cell," Journal of Crystal Growth, vol. 310, no. 22, pp. 4666-4671, 2008. 

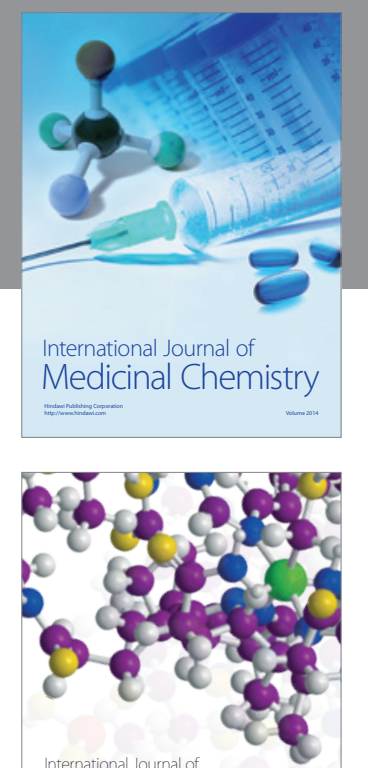

\section{Carbohydrate} Chemistry

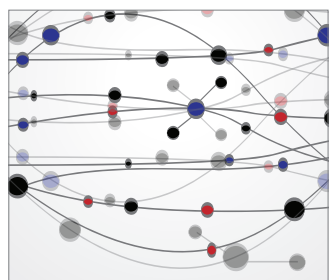

The Scientific World Journal
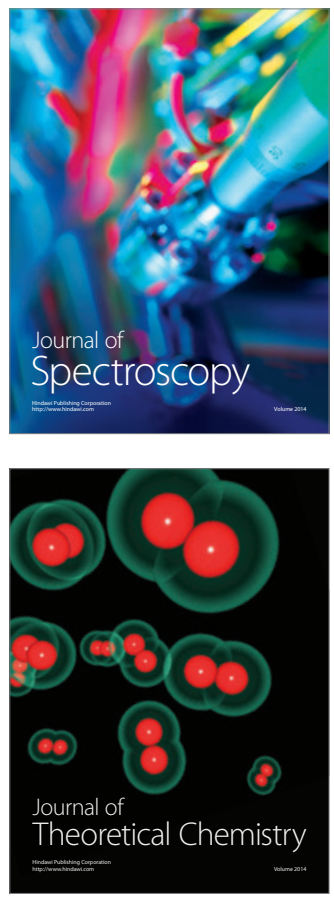
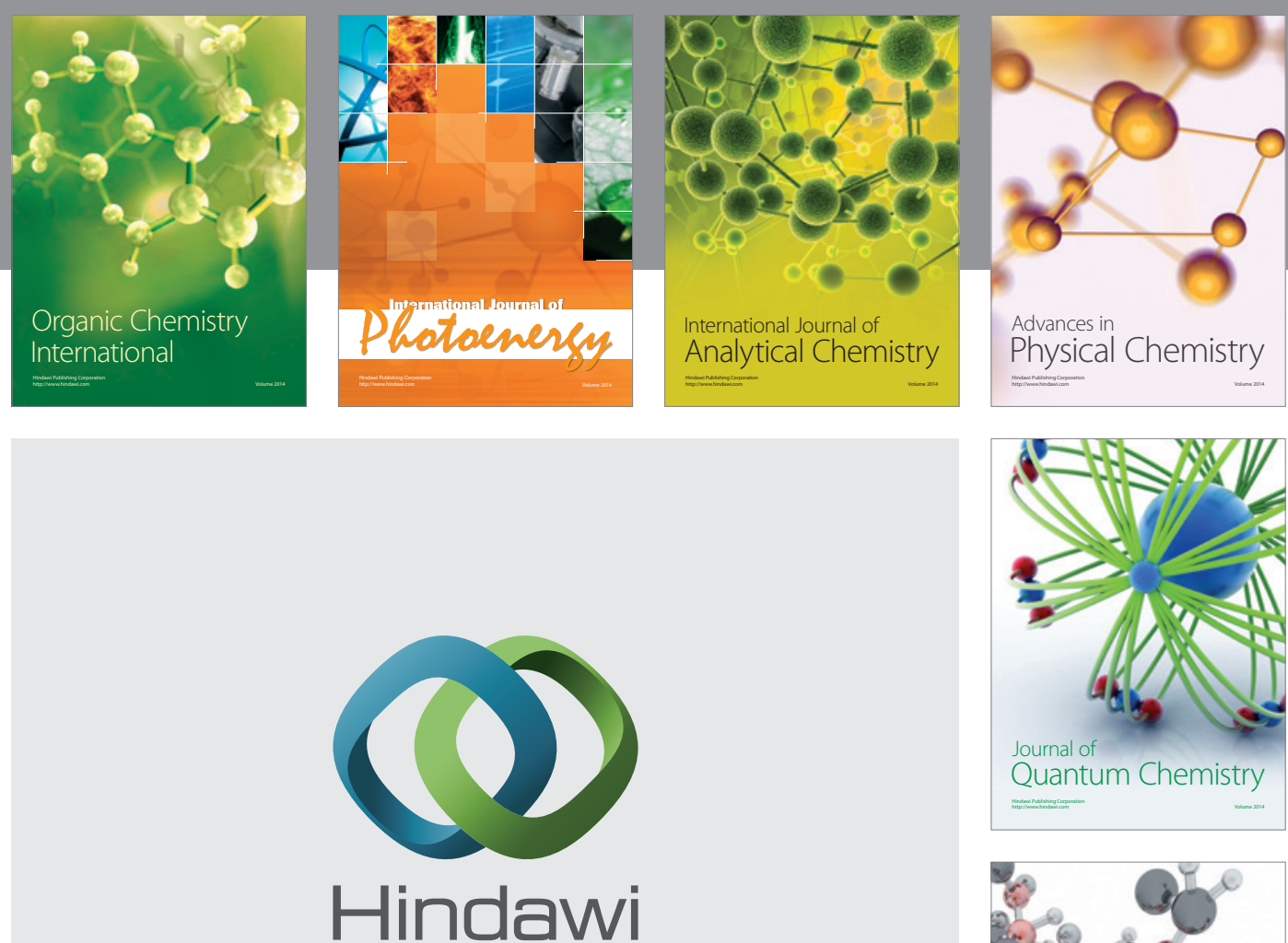

Submit your manuscripts at

http://www.hindawi.com

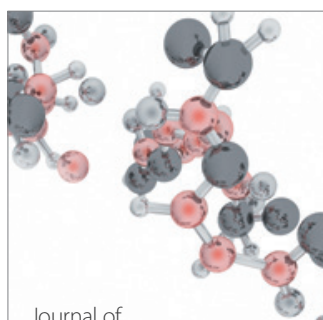

Analytical Methods

in Chemistry

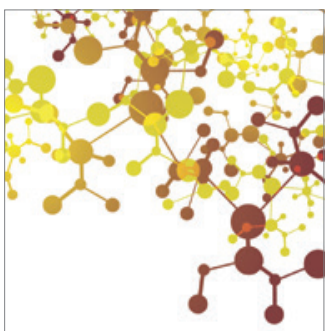

Journal of

Applied Chemistry

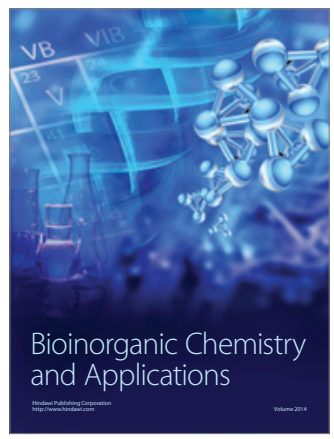

Inorganic Chemistry
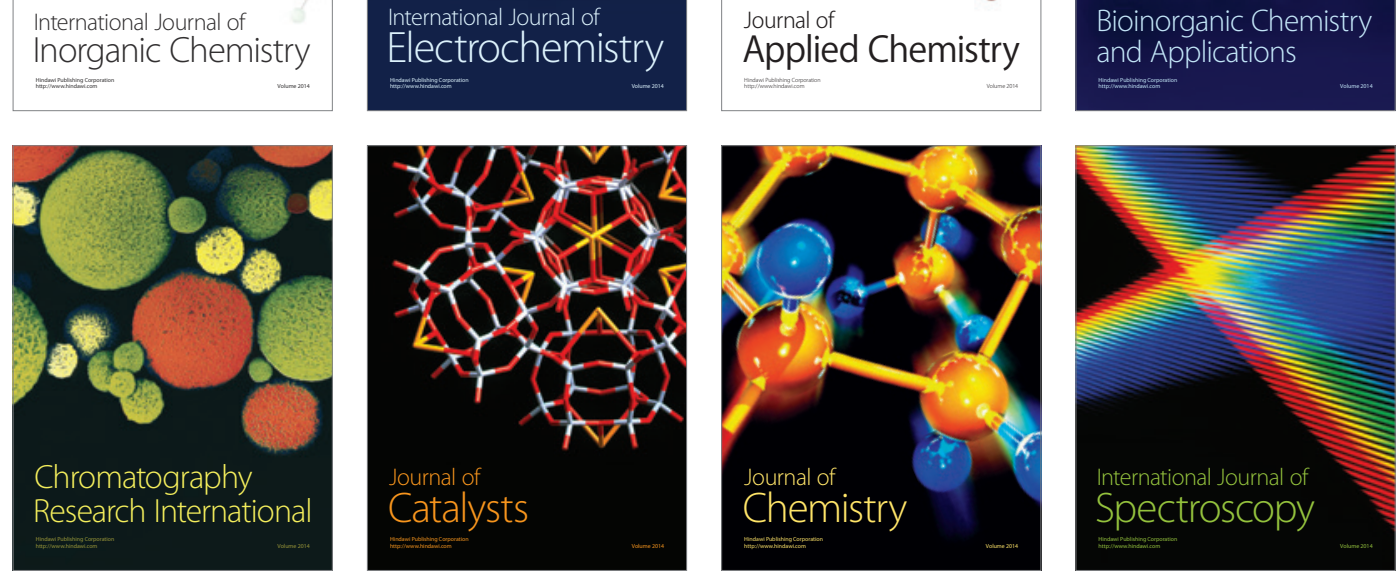